\title{
C-FRCM Jacket Confinement for RC Columns under Impressed Current Cathodic Protection
}

DOI:

10.1061/(ASCE)CC.1943-5614.0001006

\section{Document Version}

Accepted author manuscript

Link to publication record in Manchester Research Explorer

\section{Citation for published version (APA):}

Zhu, J., Wang, Z., Su, M., Ueda, T., \& Xing, F. (2020). C-FRCM Jacket Confinement for RC Columns under Impressed Current Cathodic Protection. Journal of Composites for Construction, 24(2), 04020001.

https://doi.org/10.1061/(ASCE)CC.1943-5614.0001006

\section{Published in:}

Journal of Composites for Construction

\section{Citing this paper}

Please note that where the full-text provided on Manchester Research Explorer is the Author Accepted Manuscript or Proof version this may differ from the final Published version. If citing, it is advised that you check and use the publisher's definitive version.

\section{General rights}

Copyright and moral rights for the publications made accessible in the Research Explorer are retained by the authors and/or other copyright owners and it is a condition of accessing publications that users recognise and abide by the legal requirements associated with these rights.

\section{Takedown policy}

If you believe that this document breaches copyright please refer to the University of Manchester's Takedown Procedures [http://man.ac.uk/04Y6Bo] or contact uml.scholarlycommunications@manchester.ac.uk providing relevant details, so we can investigate your claim.

\section{OPEN ACCESS}


Zhu, J.H., Wang, Z., Su, M.N., Ueda, T., Xing, F., (2020) "C-FRCM Jacket Confinement for RC Columns under Impressed Current Cathodic Protection", Journal of Composites for Construction, ASCE, 24(2), 04020001.

1

\section{C-FRCM Jacket Confinement for RC Columns under Impressed Current}

\section{Cathodic Protection}

\section{Ji-Hua ZHU ${ }^{1}$, Zhi WANG ${ }^{1}$, Mei-ni SU ${ }^{3 *}$, Tamon $\mathrm{UEDA}^{4}$, Feng XING ${ }^{5}$}

${ }^{1}$ Professor, Guangdong Province Key Laboratory of Durability for Marine Civil Engineering, College of Civil and Transportation Engineering, Shenzhen University, Shenzhen, Guangdong 518060, China. Email: zhujh@szu.edu.cn

${ }^{2}$ MSc student, Guangdong Province Key Laboratory of Durability for Marine Civil Engineering, College of Civil and Transportation Engineering, Shenzhen University, Shenzhen, Guangdong 518060, China. Email: wangzhi2017@email.szu.edu.cn

${ }^{3}$ Lecturer, School of mechanical, aerospace and civil engineering. University of Manchester, Manchester, Sackville Street, Manchester, M1 7JR, UK. Email: meini.su@manchester.ac.uk (Corresponding author)

${ }^{4}$ Professor, Laboratory of Engineering for Maintenance System, Faculty of Engineering, Hokkaido University, Sapporo 060-8628, Japan. Email: ueda@eng.hokudai.ac.jp

${ }^{5}$ Professor, Guangdong Province Key Laboratory of Durability for Marine Civil Engineering, College of Civil and Transportation Engineering, Shenzhen University, Shenzhen, Guangdong 518060, China. Email: xingf@szu.edu.cn

Abstract: In coastal regions, chloride penetration causes steel reinforcing bar (rebar) corrosion in reinforced concrete (RC) structures, leading to durability problems in existing structures. A new intervention method, impressed current cathodic protection and structural strengthening (ICCP-SS), was adopted to rehabilitate sea-sand concrete columns. A carbon 
22 fiber-reinforced cementitious matrix (C-FRCM) was used as a dual-functional material in the

23 ICCP-SS system, wherein the C-FRCM served as both an anode and a strengthening material.

24 This study aimed to consider the effects of the total charge density on the confinement effect

25 of C-FRCM jackets and the compressive strength of columns under ICCP-SS intervention to

26 demonstrate the long-term effectiveness of the ICCP-SS intervention method for sea-sand RC

27 columns and to investigate the appropriateness of existing strength models for RC columns

28 strengthened by C-FRCM jackets under ICCP. The experimental program included a total of

29 nine reinforced concrete stub columns. Prior to the compression tests, the columns were

30 subjected to 270 days of accelerated corrosion and 250 days of cathodic protection under

31 protective cathodic current densities of $20 \mathrm{~mA} / \mathrm{m}^{2}$ and $60 \mathrm{~mA} / \mathrm{m}^{2}$. This paper presented an

32 experimental program, a comparison between short-term and long-term test results of

33 ICCP-SS, a comparison of existing strength models and a discussion on the appropriateness

34 of the existing models for C-FRCM jackets subjected to an applied current.

35 Keywords: C-FRCM; carbon fiber mesh; column; corrosion; impressed current cathodic

36 protection; reinforced concrete; structural strengthening

38 Introduction

39 Concrete is the most widely used building material in the world. However, reinforced

40 concrete (RC) structures might face durability problems (Zhang et al. 2017a; Li et al. 2019),

41 most of which are caused by the corrosion of steel rebars induced by chloride ions (Mehta

42 1991). The influence of steel corrosion on an RC structure has the following aspects: First, 
rusting causes the steel volume to expand, causing the concrete to crack (Rodriguez et al. 1994); Second, when a rebar is corroded, the cross-sectional area of the rebar is reduced (Ahmad 2003); Third, the bonding performance of rebar and concrete is decreased by the corrosion (Fang et al. 2006).

Impressed current cathodic protection (ICCP) has been found to be one of the most effective technologies to prevent steel corrosion in RC structures (Lambert and Paul 1995; Pedeferri 1996). The ICCP utilizes an electric field that makes the negatively charged chloride ions in the concrete move away from the surface of the rebar to the anode, thereby inhibiting the corrosion of the rebars (Chess and Broomfield 2003). A typical ICCP system for RC structures consists of an external power supply, a cathode (i.e., the steel rebars), an anode and a complete circuit system. An ideal anode should have a low consumption rate, good electrical conductivity, easy construction and simple installation. Currently, the most popular anode materials include coated titanium anodes (Lassali et al. 1998), conductive coating anodes (Clemeña and Jackson 1998), and thermal-sprayed zinc anodes (Bullard et al. 1996). However, these conventional anodes are rather expensive. Recently, Zhu et al. (2016, 2017, 2018) proposed using carbon fiber (CF) mesh as the anode material, which utilized the good electrical conductivity and stable electrochemical properties of the CF mesh. Moreover, to ensure good electrical conduction between the CF mesh and the rebars, the bonding material is also important. A new electrically conductive cementitious matrix (Su et al. 2019a) was used in this study. By embedding a CF mesh inside a cementitious matrix, a carbon fiber-reinforced cementitious matrix (C-FRCM) composite is obtained (D'Ambrisi and 
Focacci 2011).

The confinement jackets in most previous studies were steel jackets (Susantha et al. 2001;

66

67

68

69

70

71

Kwan et al. 2016) and fiber reinforced polymer (FRP) - epoxy resin jacket (Lam and Teng 2003; Teng et al. 2007; Zhang et al. 2017b). With the study of FRCM jackets, their advantages have gradually emerged. Peled (2007) compared FRCM jackets and FRP jackets for repairing damaged concrete columns and their corresponding failure modes and mechanical responses; they found that FRCM jackets were a better choice than FRP jackets in terms of compatibility. Furthermore, a cementitious matrix can be used to fill the damaged area of a component surface. Basalo et al. (2012) used scanning electron microscopy (SEM) to study the influence of the infiltration of inorganic cementitious materials on the stress transfer, and their experimental results showed that cementitious matrix fails to effectively penetrate into the fiber bundle, but the inorganic matrix and the concrete member have good compatibility. In addition, the strength of the FRCM-confined columns increased linearly as the number of fiber layers increased, indicating that FRCM has a good confinement effect on concrete columns. Ombres (2014) investigated the influence of fiber mesh winding angles and fiber layers on the compression performance of confined concrete columns. Their experimental results showed that a winding angle of $90^{\circ}$ was the most effective among the tested angles. They introduced a winding angle reduction factor into the confining pressure prediction formula. Ludovico et al. (2010) compared four different confinement schemes on concrete cylinders: uniaxial glass FRP (GFRP) laminates, alkali-resistant fiberglass grids bonded with cement-based mortar, bidirectional basalt laminates preimpregnated with epoxy 
resin or latex and bonded with cement-based mortar, and cement-based mortar jackets. Their

86

87

88

89

90

91

92 experimental results showed that the basalt-reinforced mortar (BRM) confinement system provided concrete columns significantly better compression capacity and ductility than GFRP jackets. In addition to research at ambient temperature, Trapko (2013) studied the effects of temperature on FRCM/carbon FRP (CFRP) confinement. The failure stresses of the CFRP-confined columns decreased with increasing temperature, and the load-bearing capacity decreased by $10 \%$ for every $20{ }^{\circ} \mathrm{C}$ increase in temperature. However, the failure stress change in the FRCM-confined columns was negligible. Trapko (2013) also found that the FRCM-confined columns exhibited greater ductility than the CFRP-confined columns. In addition, there are a number of existing design standards for the capacity prediction of confined RC columns (Fib 2001; ISIS 2001; ACI 2017; GB 2013). Most of these standards (Fib 2001; ISIS 2001; ACI 2017; GB 2013) were developed based on FRP-epoxy resin jackets, whereas ACI 549.4R-13 (ACI 2013) was specifically proposed for FRCM confinement jackets. Although there are many similarities between the FRP-epoxy resin system and the FRCM system, they could have different mechanical behaviors and confinement models. Furthermore, if a C-FRCM jacket was used as the confinement material and the anode simultaneously, as proposed by Zhu et al. (2018), the long-term effects of ICCP on the C-FRCM jacket have not been studied.

Therefore, the key objectives of this study are to consider the effect of the total charge density on the confinement provided by C-FRCM jackets and the compressive strength of columns under ICCP and structural strengthening (ICCP-SS) intervention to prove the 
106 long-term effectiveness of the ICCP-SS intervention method for sea-sand RC columns and to

107 investigate the appropriateness of existing strength models for RC columns strengthened by

108 C-FRCM jackets under ICCP. First, this paper extracted the short-term behavior of RC

109 columns subjected to ICCP-SS from the literature (Zhu et al. 2018). Please note that the

110 ICCP-SS intervention method uses a dual-functional material (CF mesh) to combine cathodic

111 protection and structural strengthening as an integrated retrofitting technique ( $\mathrm{Su}$ et al.

112 2019b). Second, a new experimental program on the relatively long-term performance of RC

113 columns subjected to ICCP-SS intervention is presented. The electrochemical and mechanical

114 properties of C-FRCM should be considered because the C-FRCM composite serves as a

115 dual-functional material. The experimental results of both the short-term and long-term

116 performance are compared and discussed. The effects of the applied current density and total

117 charge quantity on the C-FRCM confinement can be subsequently analyzed. Third, the

118 experimental results were compared with the results from existing FRCM confinement

119 models. The accuracy of the existing models for C-FRCM jackets without applied current,

120 with short-term cathodic protection and with long-term cathodic protection were assessed.

121 Finally, to improve the design accuracy and simplify the design procedure, suggestions were

122 proposed to modify the existing models.

123 Data collection

124 Zhu et al. (2018) conducted the first series of short-term experiments as part of the overall

125 research project. A total of nine reinforced concrete columns were prepared with a diameter

126 of $200 \mathrm{~mm}$ and a height of $750 \mathrm{~mm}$. The specimens experienced a 90-day accelerated 
127 corrosion process and a 90-day cathodic protection process. The protective cathodic current

128 densities adopted in the study were $26 \mathrm{~mA} / \mathrm{m}^{2}$ and $80 \mathrm{~mA} / \mathrm{m}^{2}$. Zhu et al. (2018) compared the

129 performance of the newly proposed ICCP-SS intervention method with two conventional

130 intervention methods: ICCP and C-FRCM strengthening. Their results showed that by using

131 C-FRCM as a dual-functional material, ICCP-SS can inhibit steel rebar corrosion and

132 improve the loading capacities of RC columns. However, the relatively short-term

133 experimental program (Zhu et al. 2018) cannot reflect the long-term performance of the

134 ICCP-SS intervention method. The long-term ICCP operation leads to polarization on the

135 anode, which might have effects on the confinement. Therefore, this study conducts relatively

136 long-term studies and identifies the effects of applied current on C-FRCM confinement.

\section{Experimental program}

\section{Test specimens}

139 A total of nine RC columns with a diameter of $220 \mathrm{~mm}$ and a height of $660 \mathrm{~mm}$ were cast

140 from a single batch of concrete. The nominal diameter of the longitudinal rebars was $10 \mathrm{~mm}$,

141 whereas that of the stirrup was $8 \mathrm{~mm}$. The details of the internal reinforcement and the

142 dimensions of the column specimens are shown in Fig. 1.

143 The nine specimens were divided into five groups: (1) two reference specimens without

144 any $\mathrm{NaCl}(\mathrm{C} 2-\mathrm{RF}$ and $\mathrm{C} 2-\mathrm{RF}-\mathrm{R})$, (2) one specimen with $\mathrm{NaCl}$ but without any repair

145 (C2-F0-I0), (3) two specimens with $\mathrm{NaCl}$ repaired by the ICCP technique (C2-F0-I20-D250

146 and C2-F0-I60-D250), (4) one specimen with $\mathrm{NaCl}$ repaired by the SS technique (C2-F1-I0),

147 and (5) three specimens with $\mathrm{NaCl}$ repaired by the ICCP-SS technique (C2-F1-I20-D250, 
148 C2-F1-I20-D250-R and C2-F1I60-D250). The labeling system of the specimens is given in

149 Table 1 . The $\mathrm{NaCl}$ content in the concrete mix was $3 \%$ of the cement mass. After the curing

150 period, some specimens were exposed to 270-day accelerated corrosion, followed by 250-day

151 cathodic protection as designed. The protective cathodic current densities were $20 \mathrm{~mA} / \mathrm{m}^{2}$ and

$15260 \mathrm{~mA} / \mathrm{m}^{2}$.

\section{Material properties}

154 The material properties of the concrete, steel rebars, CF mesh, cementitious matrix and

155 C-FRCM composite were measured in this study. The 28-day compressive strength of

156 concrete was found to be $42 \mathrm{MPa}$, which was determined in accordance with a standard

157 cylinder test ASTM C39 (ASTM 2012); the cylinder had a diameter of $150 \mathrm{~mm}$ and a height

158 of $300 \mathrm{~mm}$. Two sizes of rebars -8 and $10 \mathrm{~mm}$ - were used in the specimens as stirrups and

159 longitudinal bars, respectively. The tensile strengths of the rebars were measured by tensile

160 tests in accordance with ASTM A370 (ASTM 2017a), and the gauge length of the rebars was

$161400 \mathrm{~mm}$. The mechanical properties of a bundle of CF meshes (12k fiber filaments for one

162 bundle) were measured based on ASTM D4018 (ASTM 2017b), and the gauge length of the

163 tested specimens was $150 \mathrm{~mm}$. The compression and flexural strengths of the proposed

164 cementitious matrix were measured in accordance with the European Committee for

165 Standardization EN1015-11 (EN 1993). Please note that the cementitious matrix used in this

166 study is different from that in the short-term study (Zhu et al. 2018). The average material

167 properties obtained from the aforementioned tests are presented in Table 2. Three repeated

168 tests were conducted to obtain each material property. 
170 internal layer of CF mesh. The mechanical properties of the C-FRCM composite were tested

171 in accordance with ACI 549.4R-13 (ACI 2013) using a $10 \mathrm{kN}$ electric-control universal

172 testing machine. The dimensions of the C-FRCM coupons were $400 \mathrm{~mm} \times 50 \mathrm{~mm} \times 10 \mathrm{~mm}$

173 (length $\times$ width $\times$ thickness) (see Fig. 2(a)), and the gauge length of the coupons was $200 \mathrm{~mm}$.

174 Previous studies (Bisby et al. 2009; Bilotta et al. 2017) found that the cracking position of

175 FRCM composite materials was highly discrete, so conventional techniques were not

176 appropriate for the strain measurement of C-FRCM composites. Strain gauges attached to the

177 specimen can measure only the local strain and might not be able to capture the strain field in

178 the cracking region, and data measured by an extensometer could be affected by the energy

179 released during the occurrence of cracks. Therefore, in this study, in addition to an 180 extensometer, a noncontact measurement technology—digital image correlation (DIC)—was

181 also used to obtain the strain field of the C-FRCM coupons during loading. The images from

182 DIC can output the visual crack development and the overall failure mode of the specimens.

183 The strain field of C-FRCM at ultimate tensile strength is shown in Fig. 2(b). Two

184 through cracks appeared on the surface of the specimen. The failure mode of the C-FRCM

185 composite was slippage between the CF mesh and the cementitious matrix, as shown in Fig. 3.

186 Fig. 4 shows the stress-strain curves of the C-FRCM composite; three parallel tests were

187 carried out for each type of C-FRCM composite. Fig. 4(a) is the C-FRCM used in the

188 short-term tests (Zhu et al. 2018), and Fig. 4(b) is the C-FRCM used in this study. The curve

189 was obtained with tests conducted in accordance with Annex A of AC434 (AC 2016) using 
190 the clevis-type grips prescribed in its provisions. Note that the tensile stress of C-FRCM is

191 the ratio of the tensile load to the cross-sectional area of the CF. The typical stress-strain

192 curves of an FRCM composite are generally bilinear. The initial linear segment of the curve

193 corresponds to the FRCM uncracked linear behavior and is characterized by the uncracked

194 tensile modulus of elasticity $E_{\text {frcm }}{ }^{*}$. The second linear segment, which corresponds to the

195 FRCM cracked linear behavior, is characterized by the cracked tensile modulus of elasticity

$196 E_{f r c m}$. According to AC434 (AC 2016), the cracked tensile modulus was derived based on two

197 points in the second part of the curve. These two points correspond to stress levels of 0.6ffu

198 and $0.9 f_{f u}\left(f_{f u}\right.$ is the ultimate tensile strength of FRCM). The results derived from C-FRCM

199 stress-strain curves are shown in Table 3.

200 Experimental program

201 An accelerated corrosion process was used to induce corrosion in the test specimens within a

202 reasonable period. A certain amount of $\mathrm{NaCl}$ (3\% chloride by weight of the cement) was

203 added to the concrete mix to simulate sea-sand concrete. This amount of sodium chloride

204 should be sufficient to initiate corrosion (Zhu et al. 2017). Please note that no sodium

205 chloride was added to the control specimens (C2-RF and C2-RF-R). Afterwards, all of the

206 specimens were placed outdoors to cure for 28 days. The specimens were subjected to a

207 wet-dry cycle twice per week (each cycle consisting of two-and-a-half wetting days and one

208 drying day). The accelerated corrosion process lasted for 270 days.

209 After the accelerated corrosion procedure, the C-FRCM jacket was bonded to columns.

210 For each confined specimen, the CF meshes have an overlap length of $200 \mathrm{~mm}$ (i.e., 
211 approximately $\mathrm{D} / 4$, where $D$ is the diameter of the specimens) (Nguyen et al. 2016) to

212 prevent premature failure of the fabric due to debonding. The C-FRCM strengthening process

213 following the same steps as that used in Zhu et al. (2018): (1) sandblast the concrete surface

214 to remove any surface grease, laitance and heterogeneous parts, (2) apply a layer of

215 cement-based mortar with a thickness of $3 \mathrm{~mm}$, (3) wrap one layer of CF mesh around the

216 column, and (4) apply a second layer of cement-based mortar with a nominal thickness of 3

$217 \mathrm{~mm}$ on top of the CF mesh (see Fig. 5(a)). Afterwards, a ribbed roller was used in both the

218 hoop and longitudinal directions to facilitate impregnation. Specimens were cured for 28 days

219 before the application of ICCP. The ICCP was applied to columns by connecting the steel

220 rebars to the negative terminal and the CF mesh anode to the positive terminal of a direct

221 current (DC) power supply. The ICCP systems were operated in an open area for 250 days

222 (Fig. 5(b)).

\section{Compression tests}

224 All specimens were powered down and the wet-dry cycle was simultaneously stopped before

225 testing. All specimens were tested under uniaxial compression at a controlled displacement

226 rate of $0.3 \mathrm{~mm} / \mathrm{min}$ in accordance with ASTM C39 (ASTM 2012). Axial deformation was

227 measured with three linear variable differential transducers (LVDTs) located between the

228 upper and lower end plates. Transverse deformation was measured with LVDTs mounted on

229 two opposite sides of the specimen. A total of nine strain gauges were attached to the CF

230 mesh to measure the strain of the CF mesh (Fig. 6). 


\section{Experimental results}

\section{Results of ICCP}

233 By measuring the open circuit potential, corrosion rate and corrosion current density of the

234 rebars, the corrosion status of the rebars in the columns could be evaluated. ASTM C876

235 (ASTM 2015) classifies the corrosion state of rebars according to their measured open circuit

236 potentials (see Table 4). In addition, Grantham et al. (1997) also proposed classifying the

237 corrosion state of rebars based on the measured corrosion current density and corrosion rate

238 (see Table 4).

239 The open circuit potentials of the rebars were measured and recorded, as shown in Fig. 7.

240 The open circuit potentials of the rebars in the reference columns (C2-RF and C2-RF-R) were

241 found to be approximately $-100 \mathrm{mV}$, which indicated that the probability of corrosion was

242 less than $10 \%$ and able to be ignored. The open circuit potentials of the rebars in the corroded

243 specimens without any treatment (C2-F0-I0 and C2-F1-I0) were found to be approximately

$244-270 \mathrm{mV}$, which meant that the probability of corrosion was approximately $50 \%$ and that the

245 rebars were moderately corroded. In contrast, the open circuit potentials of the rebars from

246 the ICCP-protected columns (C2-F0-I20-D250, C2-F1-I20-D250, C2-F1-I20-D250-R,

247 C2-F0-I60-D250 and C2-F1-I60-D250) were approximately $-270 \mathrm{mV}$ before the ICCP

248 application and rose to $-170 \mathrm{mV}$ after the ICCP application. This finding indicates that the

249 application of ICCP reduced the possibility of rebar corrosion.

250 The corrosion rates of the rebars were measured and recorded, as shown in Fig. 8. The

251 corrosion rates of the rebars in the reference columns were found to be approximately 5.5 
$252 \mu \mathrm{m} /$ year. The corrosion rates of the rebars in the corroded specimens without any treatment

253 were $23 \mu \mathrm{m} / \mathrm{year}$. In contrast, for other columns, the corrosion rates of the rebars were found

254 to be approximately $23 \mu \mathrm{m} /$ year before the application of ICCP and $5.5 \mu \mathrm{m} / \mathrm{year}$ after the

255 application of ICCP, which clearly indicates the effectiveness of ICCP on the protection of

256 steel reinforcement.

257 The corrosion current densities of the rebars were also measured and recorded, as shown

258 in Fig. 9. The corrosion current densities of the rebars in the reference columns were found to

259 be approximately $0.5-1.0 \mu \mathrm{A} / \mathrm{cm}^{2}$, which indicates slightly corrosive conditions. The

260 corrosion current densities of the rebars in the corroded specimens without any treatment

261 were approximately $4.0 \mu \mathrm{A} / \mathrm{cm}^{2}$. After the application of ICCP, the corrosion current densities

262 of those protected columns decreased to less than $1.0 \mu \mathrm{A} / \mathrm{cm}^{2}$. Similarly, the measured results

263 of corrosion current densities also demonstrated that ICCP can successfully protect the rebars

264 in columns under corrosive environments.

265 After compression testing, the rebars were removed from the tested columns to measure

266 the linear density reduction due to corrosion. The rebars were cleaned and weighed in

267 accordance with ASTM G1 (ASTM 2011) (Fig. 10). The rebar mass loss results are shown in

268 Table 5. For the specimens containing $\mathrm{NaCl}$ and protected by ICCP, the mass loss in the rebar

269 was less than $2 \%$, whereas for specimens containing $\mathrm{NaCl}$ without ICCP, the mass loss was

270 between $3.5 \%$ and $4 \%$. In conclusion, when C-FRCM composite is used as the anode

271 material, ICCP can effectively prevent further corrosion of the rebars even in corrosive

272 environments. 


\section{$\underline{\text { Results of compression tests }}$}

274 For the unconfined columns, sudden failure occurred due to concrete crushing (Fig. 11(a)).

275 Regarding C-FRCM-confined columns, the failure of the columns occurred in a more gradual

276 manner. Initially, a main vertical crack in the cementitious material propagated slowly on the

277 column surface. The confined column failed when the crack widened and the CF mesh

278 ruptured in the hoop direction (Fig. 11(b)). This failure mode is similar to that in the

279 observations reported by Zhu et al. (2018) and Ombres and Mazzuca (2017).

280 The load-deformation curves of all specimens are plotted in Fig. 12, and the experimental

281 results are summarized in Table 6. The initial part of the load-deformation curves at low

282 strains were similar among the reference columns and strengthened columns because the

283 compression loads were mainly resisted by the concrete cores and the C-FRCM jacket did not

284 effectively work yet. As the loads approaching the ultimate strength, the load-deformation

285 curves of the ICCP-SS strengthened columns departed from those of the unconfined columns,

286 and the C-FRCM jacket gradually developed its confinement effect. For the reference

287 columns (C2-RF and C2-RF-R), the load capacities were found to be $1804 \mathrm{kN}$ and $1771 \mathrm{kN}$

288 (average load $=1787 \mathrm{kN}$ ), respectively. The capacity of the corroded specimen without any

289 treatment (C2-F0-I0) was $1746 \mathrm{kN}$, which was $2.32 \%$ lower than that of the reference column,

290 attributing to the reduction in the rebar cross section. For specimens that were protected only

291 by ICCP (C2-F0-I20-D250 and C2-F0-I60-D250), the compression load capacities were

$2927.42 \%$ higher than that of the corroded specimen C2-F0-I0, which demonstrates that ICCP

293 can effectively impede further corrosion in the rebars. The load capacity of the column 
294 strengthened only by C-FRCM (C2-F1-I0) was $2069 \mathrm{kN}$, which was $15.75 \%$ higher than that

295 of the reference columns (C2-RF and C2-RF-R). The results showed that the C-FRCM jacket

296 could effectively improve the loading capacity of degraded columns. The three columns

297 retrofitted by the ICCP-SS method (C2-F1-I20-D250, C2-F1-I20-D250-R, and

298 C2-F1-I60-D250) exhibited 24-37\% greater loading capacities than the reference columns

299 (C2-RF and C2-RF-R).

300 Comparison between short-term and long-term performance of the ICCP-SS

301 intervention method

302 Ultimate strength improvement

303 To compare the effect of ICCP on C-FRCM confinement, the relationships between the

304 applied current density, protection duration and charge quantity and the ultimate strength

305 increase percentage (compared to reference column) were studied and are plotted in Fig. 13,

306 which included both the short-term and long-term test results. The ultimate capacity

307 enhancement increases as the current density and protection time increase. Fig. 13(a) shows

308 that a larger current density leads to greater capacity enhancement, especially for confined

309 columns; for unconfined columns, the capacity enhancements were generally the same. Table

3107 shows that for the C-FRCM confined column, the ultimate strength increase rate increases

311 with increasing charge density. This finding indicated that the larger charge density can lead

312 to a lower corrosion rate of the steel rebars and less stress concentration on the C-FRCM

313 interface, thereby achieving better mechanical properties with the C-FRCM. The application

314 of ICCP technology may cause degradation in the C-FRCM interface of the anode material, 
315 which will result in a more uniform stress distribution and less stress concentration of the

316 C-FRCM jacket during the loading process. Therefore, the effect of premature failure of the

317 fiber mesh could be reduced, indirectly improving the confinement effect. Fig. 13(b) shows

318 that a longer protection duration leads to greater capacity enhancement: the capacity

319 enhancement of the confined columns in this study was higher than that of the confined

320 columns in the short-term tests (Zhu et al. 2018). The results indicate that the cementitious

321 matrix in this study might have positive effects on the C-FRCM confinement. To make the

322 comparison more straightforward, Fig. 13(c) displays the compression capacity improvement

323 with respect to the charge density applied to the C-FRCM jacket. For ICCP-protected

324 columns, the capacity enhancements were mainly due to the successful protection of the steel

325 rebars and were found to be slightly improved as the charge density increased. The

326 compression resistance enhancement when the charge density increased was more

327 pronounced in the ICCP-SS-protected columns than in the ICCP-protected columns, which is

328 indicated by the different slopes of the hollow dots (ICCP specimens) and solid dots

329 (ICCP-SS specimens) in Fig. 13(c), which again revealed that larger charge density not only

330 prevents the steel rebars from corroding but also leads to better confinement effects of the

331 C-FRCM jacket.

332 Effective strain of CFs

333 For C-FRCM jackets, the measured ultimate strain of the CF wrapped on the column was

334 lower than the ultimate strain measured from the tensile tests due to different loading 335 configurations, which leads to an analysis of the efficiency of the C-FRCM jacket. The 
336 efficiency of the FRCM composite is an indicator of the confinement effect of the FRCM

337 jacket. This study defines the FRCM strain efficiency factor $\left(k_{e}\right)$ as the ratio of the ultimate 338 hoop strain of the FRCM jacket $\left(\varepsilon_{f l}\right)$ to the ultimate tensile strain of the FRCM coupon $\left(\varepsilon_{f u}\right)$,

339 i.e., $k_{e}=\varepsilon_{f l} / \varepsilon_{f u}$. The hoop strain and strain efficiency factor of both short-term and long-term

340 specimens are presented in Table 8. The efficiency of the C-FRCM jacket after long-term

341 cathodic protection is greater than that in the short-term condition. In addition, the C-FRCM

342 tensile test results show that the performance of the second series of C-FRCM composites is

343 better than the first series of C-FRCM composites, wherein the former has greater ultimate

344 strength and strain (see Table 3 and Fig. 4). Note that since the fracture location of CFs is

345 unknown, it is difficult to accurately capture the ultimate strain of CFs via strain gauges.

346 However, this conclusion can be generally validated by the better C-FRCM confinement with

347 larger charge density, for which a detailed explanation is given as follows. The manual

348 implementation of the C-FRCM jacket might cause imperfections in the bonding interface

349 due to poor workmanship, which resulted in localized stress concentration. The applied

350 currents during ICCP might cause the degradation of the anodic surface (i.e., C-FRCM

351 jacket), which could release the stress concentration and lead to more uniform strain

352 development in the confining jacket. Thus, the degraded bonding after ICCP may delay the

353 fiber fracture, resulting in a better confinement effect.

\section{Existing prediction models of confined strength}

355 The confined concrete column expands under axial loads. On the one hand, the C-FRCM

356 jacket deforms circumferentially and generates tensile stress in the hoop direction; on the 
other hand, the C-FRCM jacket limits the expansion of the core concrete column, so that the core concrete is subjected to a three-direction loading state, thereby improving the axial loading capacity. The compressive strength of confined concrete $\left(f_{\text {cc }}\right)$ under active confinement can be expressed in a nondimensional form, as given by Eq. 1 (Thériault et al. calculated with Eq. 2.

$$
\frac{f_{c c}}{f_{c o}}=1+k\left(\frac{f_{l u}}{f_{c o}}\right)^{\alpha}
$$

$$
f_{l u}=\frac{2 n t f_{t}}{D}
$$

where $f_{\mathrm{cc}}$ is the compressive strength of the confined concrete, $f_{c o}$ is the compressive strength of the concrete, $f_{l u}$ is the confining pressure exerted by the confinement material, $k$ and $\alpha$ are empirical constants to be calibrated through a best-fit analysis to minimize the difference between the predicted and experimental strength capacities, $n$ is the number of layers of the confinement material, $t$ is the thickness of the confinement material, $f_{t}$ is the tensile strength of the confinement material, and $D$ is the diameter of the specimens.

\section{Existing models}

372 The confinement models are different for different confining materials, such as steel jackets

373 (Susantha et al. 2001; Kwan et al. 2016), FRP-epoxy jackets (Lam and Teng 2003; Teng et al. 2007) and FRCM jackets (Peled 2007). Since this study focused on C-FRCM jackets, only the existing confinement models developed for FRCM jackets are considered herein, including the ACI model codified in ACI 549.4R-13 (ACI 2013), the OM model proposed by 
shown in Eqs. 3-4.

$$
\frac{f_{c c}}{f_{c o}}=1+3.1 \frac{f_{l u}}{f_{c o}}
$$

$$
f_{l u}=\frac{2 n A_{f} E_{f r c m} \varepsilon_{f e}}{D}
$$

where $A_{f}$ is the area of the mesh reinforcement by unit width; $E_{f r c m}$ is the tensile modulus of

elasticity of the cracked FRCM; $\varepsilon_{f e}$ is the effective strain of the FRCM composite material at tensile strain of the FRCM.

Recently, Ombres and Mazzuca (2017) extracted a total of 152 experimental results on

FRCM-confined concrete cylinders from the literature. Moreover, they proposed a prediction model for FRCM jackets, term herein as the OM model, based on the collected experimental data. An efficiency factor accounting for the reduction in the effective strain of the $\mathrm{CF}$ in the hoop direction was adopted in this model, as shown in Eqs. 5-7.

$$
\frac{f_{c c}}{f_{c o}}=1+0.913\left(\frac{f_{l u}}{f_{c o}}\right)^{0.5}
$$

$$
f_{l u}=\frac{2 n t E_{f} k_{e} \varepsilon_{f}}{D}
$$

$$
k_{e}=0.25\left[\left(\frac{\rho_{f} E_{f}}{f_{c o}}\right)^{0.3}-1\right]
$$

where $E_{f}$ is the longitudinal elastic modulus of the fiber reinforcement, $\varepsilon_{f}$ is the ultimate tensile strain of the fiber, and $\rho_{f}$ is the FRCM reinforcement ratio $\left(\rho_{f}=4 n t / D\right)$. In addition, $k e^{\prime}$ is 0.335 in the first series of tests (Zhu et al. 2018), whereas $k e^{\prime}$ is 0.320 in this study. 
The TR model is depicted in Eqs. 8-9.

$$
f_{l u}=\frac{2 n t f_{f u}}{D}
$$

where $f_{f u}$ is the ultimate tensile strength of the FRCM.

\section{Result comparisons}

407 The three considered models are used to predict the confined concrete strengths of the tested

408 columns considered in this paper. Note that the experimental ultimate stress $f_{c c}$ is calculated by Eq. 10 in this paper.

410

$$
N=f_{c c}\left(A_{g}-A_{s}\right)+f_{y} A_{s}
$$

411 where $N$ is the axial bearing capacity of the RC columns, $A_{g}$ is the gross cross-sectional area

412 of the compression column, $A_{s}$ is the total area of the longitudinal steel bars, and $f_{y}$ is the 413 tensile yield strength of the steel.

414 Based on Eq. 10, the contribution of the longitudinal steel bars has been excluded in the 415 calculation process. After compression testing, the corroded steel rebars were removed from 416 the columns for weighing and tensile tests so that the corrosion rate of the steel rebars was 
417 measured and the material properties of corroded rebars could be obtained and used in Eq. 10.

418 The measured material properties and dimensions are used in the calculation. The predicted

419 confined concrete strengths are compared with the test results in Fig. 15. This comparison

420 revealed that all three models underestimated the confinement strengths provided by the

421 C-FRCM jacket; note that the OM model (Ombres and Mazzuca 2017) seems to be slightly

422 more accurate than the other two models (Triantafillou et al. 2006; ACI 2013). Moreover, the

423 conservatism of the three models is more pronounced when the specimen is subjected to

424 larger charge density during ICCP. The results of the confined columns without ICCP

425 protection are closest to the prediction curve. The results show that within the scope of this

426 study (applied cathodic current densities ranging from $20 \mathrm{~mA} / \mathrm{m}^{2}$ to $60 \mathrm{~mA} / \mathrm{m}^{2}$ ), the

427 application of a protective current further improves the carrying capacity of

428 C-FRCM-confined concrete columns, and the loading capacity improved as the protective

429 current increased. Therefore, the existing models cannot accurately capture the improved

430 confinement in the presence of ICCP. Hence, modifications are needed to extend the existing

431 models for the prediction of the C-FRCM jacket after ICCP.

\section{Suggestion for model modification}

433 Fig. 4 shows that the bilinear stress-strain response of the C-FRCM composite is different

434 from the elastic stress-strain curves of CF bundles (Arboleda 2014). The behavior of the

435 C-FRCM jacket not only relates to the embedded CF mesh but also the bonding interface

436 between the $\mathrm{CF}$ mesh and the cementitious matrix. The experimental program showed that

437 the failure mode of the C-FRCM composite plate is not a complete fracture of the embedded 
CF; instead, the failure mode is a combination of CF rupture and slippage between CF mesh and cementitious matrix. The results showed that the measured strains $\left(\varepsilon_{f e}\right)$ of the embedded

$440 \mathrm{CF}$ at ultimate loads in the column tests were generally lower than those from the tensile tests

$441\left(\varepsilon_{f u}\right)$ because it is difficult to precisely capture the strain of embedded CF meshes at the 442 critical locations (Bilotta et al. 2017) even using strain gauges, extensometers and DIC 443 techniques. In addition, given that the effective strain is obtained, the modulus of the material 444 is also needed. Currently, some models suggested using the modulus of the embedded CF, 445 whereas others suggested using the modulus of the C-FRCM composite. Therefore, to avoid the inaccurate estimation of the C-FRCM strain distribution and the unclear selection of the modulus, it is suggested to use the C-FRCM ultimate strength in the confining pressure prediction, as shown in Eq. 11. Please note that the ultimate strength of C-FRCM herein is defined as the strength obtained by the tension tests of the C-FRCM composite coupons, where $f_{c-f r c m}$ is the ultimate tensile strength of the C-FRCM composite coupons.

$$
f_{l u}=\frac{2 n t f_{c-f r c m}}{D}
$$
confinement since the C-FRCM also serves as the anode. The reasons for the positive effects are related to the more uniform stress distribution in the C-FRCM jacket, which leads to better utilization efficiency of the embedded $\mathrm{CF}$ mesh. To include this effect in the confinement model, it is suggested to adjust the $k$ value in Eq. 1 when considering the C-FRCM jacket under different anodic polarization, i.e., different charge densities during 

2013) and 1.27 (Triantafillou et al. 2006), the $k$ value is derived for each column, as shown in Table 9 and Fig. 16. By observation, it is found that there is a linear relationship between the $k$ value and the total charge density $(Q)$. Equations showing the relationship between the $k$ value and the total charge density $(Q)$ were obtained by regression fitting, as shown in Fig. 16 and given in Eqs. 12, 13 and 14 for exponents $(\alpha)$ equal to 0.5, 1.0 and 1.27, respectively.

The proposed confinement models using Eq. 11 to calculate the confining pressures $f_{l u}$ and Eqs. 12-14 to calculate the $k$ values are compared with the experimental results in Fig. 17.

470 The experimental data points are much closer to the proposed models in Fig. 17 than to the

471 existing models in Fig. 15. Hence, it is suggested to use the proposed confinement model for 472 the design of C-FRCM-confined columns under cathodic protection.

\section{Conclusions}

474 A dual-functional intervention method, ICCP-SS, has been applied to a series of RC columns 475 in a chloride-induced corrosive environment. This study includes an experimental program to 476 validate the effectiveness of this new intervention method on steel reinforcement protection 477 and loading capacity improvement. The behaviors of these columns were obtained after 250 478 days of cathodic protection. Moreover, experimental data of RC columns protected by the 479 ICCP-SS method in a short-term timeframe were extracted from the literature and used in this 
study for comparison purposes. By comparison, the potential effects of applied current on the confinement of C-FRCM jackets have been investigated. Compression test results showed that the loading capacities of the columns retrofitted by the ICCP-SS method were up to $40 \%$ greater than those of the corroded columns without any protection. In addition, a comparison of the experimental results with the predictions by different C-FRCM confinement models shows that the three considered models underestimated the confinement effects provided by the C-FRCM jacket. This paper proposes to use the C-FRCM ultimate strength instead of the

487 CF ultimate strength in the confining pressure calculation. Herein, the confinement model 488 estimating the confined concrete strength is modified based on the ultimate strength of the C-FRCM, which is obtained from tensile tests of composite coupons. For the three exponents used in the existing confinement models, corresponding $k$ values are derived. The results

491 show that there is a linear relationship between the $k$ value and the electric charge from the 492 ICCP system: the greater the charge density is, the better confinement enhancement. 493 Therefore, it is suggested to consider the effects of applied currents in the $k$ value. The newly 494 modified confinement models were compared to the experimental results, and the predictions 495 made by the modified models were closer to the experimental results than the predictions 496 made by the existing models. The relationships between the $k$ value and the charge density 497 for the confinement model obtained herein can be used for the design of ICCP-SS-protected 498 columns in future engineering applications.

\section{Acknowledgements}

500 The research work described in this paper was supported by the National Natural Science 
501 Foundation China (51778370, 51538007), the Key Project of Department of Education of

502 Guangdong Province (2017B030311004) and the Shenzhen science and technology project

$503 \quad($ JCYJ20170818094820689)

\section{Notations}

$505 A_{f}=$ area of mesh reinforcement by unit width

$506 A_{g}=$ the gross cross-sectional area of compression column

$507 A_{s}=$ the total area of longitudinal steel bars

$508 D=$ diameter of compression member

$509 E_{f}=$ longitudinal elastic modulus of fiber reinforcement

$510 \quad E_{f r c m}=$ tensile modulus of elasticity of cracked FRCM

$511 E_{\text {frcm }} *=$ tensile modulus of elasticity of uncracked FRCM

$512 f_{c c}=$ maximum compressive strength of confined concrete

$513 f_{c o}=$ specified compressive strength of concrete

$514 f_{c-f r c m}=$ ultimate tensile strength of C-FRCM composite coupons

$515 f_{f u}=$ ultimate tensile strength of FRCM

$516 f_{l u}=$ confining pressure exerted by FRCM jacket at maximum axial stress

$517 f_{t}=$ the tensile strength of the confinement material

$518 f_{y}=$ the steel tensile yield strength

$519 k=$ empirical constants to be calibrated through a best-fit analysis

$520 \quad k_{e}=$ the strain efficiency factor

$521 k_{e}{ }^{\prime}=$ the calculated value of the strain efficiency factor proposed by the OM model

$522 n=$ number of layers of mesh reinforcement

$523 N=$ the axial bearing capacity of reinforced concrete columns

$524 Q=$ charge density

$525 t=$ thickness of the fabric mesh

$526 \alpha=$ empirical constants to be calibrated through a best-fit analysis

$527 \varepsilon_{f}=$ ultimate tensile strain of fiber 
$528 \varepsilon_{f e}=$ effective tensile strain level in FRCM composite material attained at failure

$529 \varepsilon \varepsilon_{f d}=$ design tensile strain of FRCM

$530 \varepsilon f u=$ ultimate tensile strain of FRCM coupon

$531 \rho_{f}=$ the FRCM reinforcement ratio $(=4 n t / D)$

\section{References}

533 AC (Acceptance Criteria). (2016). Acceptance criteria for masonry and concrete 534 strengthening using fabric-reinforced cementitious matrix (FRCM) and steel reinforced grout 535 (SRG) composite systems. AC434. Brea, CA: ICC Evaluation Service.

536 ACI (American Concrete Institute). (2013). Guide to design and construction of externally 537 bonded fabric-reinforced cementitious matrix systems for repair and strengthening concrete 538 and masonry structures. ACI 549.4 R-13. ACI Committee 549, Farmington, MI.

539 ACI (American Concrete Institute). (2017). Guide for the design and construction of 540 externally bonded FRP systems for strengthening concrete structures. ACI 440.2R-02. 541 Farmington, MI.

542 Ahmad, S. (2003). "Reinforcement corrosion in concrete structures, its monitoring and 543 service life prediction—a review." Cem. Concr. Compos. 25(4): 459-471.

544 Arboleda, D. (2014). "Fabric reinforced cementitious matrix (FRCM) composites for 545 infrastructure strengthening and rehabilitation: Characterization methods." $\mathrm{PhD}$ thesis, 546 University of Miami.

547 ASTM (2011). Standard Practice for preparing, cleaning, and evaluating corrosion test 548 specimens. ASTM G1-03. United States.

549 ASTM (2012). Standard test method for compressive strength of cylindrical concrete 550 specimens. ASTM C39-12. United States.

551 ASTM (2015). Standard Test Method for Half-Cell Potentials of Uncoated Reinforcing Steel 552 in Concrete. ASTM C876-15. United States.

553 ASTM (2017a). Standard test methods and definitions for mechanical testing of steel 554 products. ASTM A370-17. United States.

555 ASTM (2017b). Standard test methods for properties of continuous filament carbon and graphite fiber tows. ASTM D4018-17. United States. 
557 Basalo, F. J. D. C., Matta, F., and Nanni, A. (2012). "Fiber reinforced cement-based 558 composite system for concrete confinement." Constr. Build. Mater. 32(7): 55-65.

559 Bilotta, A., Ceroni, F., Lignola, G. P., and Prota, A. (2017). "Use of DIC technique for 560 investigating the behaviour of FRCM materials for strengthening masonry elements." 561 Composites Part B. 129: 251-270.

562 Bisby, L. A., Roy, E. C., Ward M, and Stratford, T. J. (2009). "Fibre Reinforced Cementitious 563 Matrix Systems for Fire-Safe Flexural Strengthening of Concrete: Pilot Testing at Ambient 564 Temperatures." Proceedings advanced composites in construction. Edinburgh, UK.

565 Bullard, S. J., Covino Jr, B. S., Cramer, S. D., McGill, G. E. (1996). Thermal-Sprayed Zinc 566 Anodes for Cathodic Protection of Steel-Reinforced Concrete Bridges. No. 567 DOE/ARC-1996-004. Albany Research Center (ARC), Albany, OR; Oregon Department of 568 Transportation, Salem, OR.

569 Chess, P. M., and Broomfield, J. P. (2003). Cathodic Protection of Steel in Concrete. CRC $570 \quad$ Press

571 Clemeña, G., and Jackson, D. (1998). "Long-Term Performance of Conductive-Paint Anodes 572 in Cathodic Protection Systems for Inland Concrete Piers in Virginia." Transport. Res. Rec. 573 1642(1): 43-50.

574 D'Ambrisi, A., and F. Focacci. (2011). "Flexural strengthening of RC beams with 575 cement-based composites." J. Compos. Constr. 15(5): 707-720.

576 EN (1993). Methods of Test for Mortar for Masonry-Part 11: Determination of Flexural and 577 Compressive Strength of Hardened Mortar. EN1015-11. Brussels, European Committee for 578 Standardization.

579 Fang, C., Lundgren, K., Plos, M., and Gylltoft, K. (2006). "Bond behaviour of corroded 580 reinforcing steel bars in concrete." Cem. Concr. Res. 36(10): 1931-1938.

581 Fib (2001). Externally bonded FRP reinforcement for $R C$ structures. Technical report bulletin 582 14, the International Federation for Structural Concrete, Switzerland. GB (2013). Code for design of strengthening concrete structures. GB50367-2013. China.

584 Grantham, M. G., Herts, B., and Broomfield, D. J. (1997). "The use of linear polarisation 585 corrosion rate measurements in aiding rehabilitation options for the deck slabs of a reinforced concrete underground car park." Constr. Build. Mater. 11(4): 215-224.

587 ISIS (2001). ISIS Canada Design Manual No. 4: Strengthening reinforced concrete structures 
with externally-bonded fiber reinforced polymers. Winnipeg, Canada.

589 Kwan, A. K. H., Dong, C. X., and Ho, J. C. M. (2016). "Axial and lateral stress-strain model 590 for concrete-filled steel tubes.” J. Constr. Steel. Res, 122: 421-433.

591 Lambert and Paul (1995). "Cathodic protection of reinforced concrete" Anti-Corros. Method. 592 M. 42(4): 4-5.

593 Lam, L., and Teng, J. G. (2003). "Design-oriented stress-strain model for FRP-confined 594 concrete." Constr. Build. Mater. 17(6-7): 471-489.

595 Lassali, T. A. F. Castro, S. C. D., and Boodts, J. F. C. (1998). "Structural, morphological and 596 surface properties as a function of composition of $\mathrm{Ru}+\mathrm{Ti}+\mathrm{Pt}$ mixed-oxide electrodes." 597 Electrochim. Acta. 43(16-17): 2515-2525.

598 Li, L.Z., Liu, X., Yu, J.T., Lu, Z.D., Su, M.N., Liao, J.H., and Xia, M. (2019). "Experimental 599 study on seismic performance of post-fire reinforced concrete frames." Eng. Struct. 179(1): 600 161-173.

601 Ludovico, M. D., Prota, A., and Manfredi, G. (2010). "Structural Upgrade Using Basalt 602 Fibers for Concrete Confinement." Journal of Composites for Construction J. Compos. 603 Constr. 14(5): 541-552.

604 Mehta, P. K. (1991). "Durability of concrete-fifty years of progress.” NISP. S P. 126: 1-32.

605 Nguyen, C. V., Lambert, P., Mangat, P. S., O’Flaherty, F. J., and Jones, G. (2016). 606 "Near-surface mounted carbon fibre rod used for combined strengthening and cathodic 607 protection for reinforced concrete structures." Struct. Infrastruct. E. 12(3), 356-365.

608 Ombres, L. (2014). "Concrete confinement with a cement based high strength composite 609 material." Compos. Struc. 109(6): 294-304.

610 Ombres, L., and Mazzuca, S. (2017). "Confined Concrete Elements with Cement-Based 611 Composites: Confinement Effectiveness and Prediction Models." J. Compos. Constr. 21(3): 61204016103.

613 Pedeferri, P. (1996). "Cathodic protection and cathodic prevention." Constr. Build. Mater. 614 10(5): 391-402.

615 Peled, A. (2007). "Confinement of Damaged and Nondamaged Structural Concrete with FRP 616 and TRC Sleeves.” J. Compos. Constr. 11(5): 514-522.

617 Rodriguez, J., Ortega, L. M., and Casal, J. (1994), “Corrosion of reinforcing bars and service 
618 life of reinforced concrete structures: Corrosion and bond deterioration." International 619 conference on concrete across borders, Odense, Denmark. Vol. 2.

620 Su, M., Wei, L. L., Zeng, Z. W., Ueda, T., Xing, F., and Zhu, J. H. (2019a). “A solution for 621 sea-sand reinforced concrete beams.” Constr. Build. Mater. 204 (2019): 586-596.

622 Su, M., Wei, L, Zhu, J.H., Ueda T., Guo G. and Xing, F. (2019b), “Combined Impressed 623 Current Cathodic Protection and FRCM Strengthening for Corrosion-Prone Concrete 624 Structures.” J. Compos. Constr. 23(4): 04019021.

625 Susantha, K. A. S., Ge, H., and Usami, T. (2001), "Uniaxial stress-strain relationship of 626 concrete confined by various shaped steel tubes.” Eng. Struct. 23(10): 1331-1347.

627 Teng, J. G., Huang, Y. L., Lam, L., and Ye, L. P. (2007). "Theoretical Model for 628 Fiber-Reinforced Polymer-Confined Concrete.” J. Compos. Constr. 11(2): 201-210.

629 Thériault, M., Neale, K. W., and Claude, S. (2004). "Fiber-Reinforced Polymer-Confined 630 Circular Concrete Columns: Investigation of Size and Slenderness Effects." J. Compos. 631 Constr. 8(4): 323-331.

632 Trapko, T. (2013). "The effect of high temperature on the performance of CFRP and FRCM 633 confined concrete elements." Composites Part B. 54(1): 138-145.

634 Triantafillou, T. C., Papanicolaou, C. G., Zissimopoulos, P., and Laourdekis, T. (2006). 635 "Concrete Confinement with Textile-Reinforced Mortar Jackets." ACI Struct. J. 103(1): $636 \quad 28-37$.

637 Zhang, D., Rashid, K., Wang B, Ueda, T. (2017a). "Experimental and analytical investigation 638 of crack spacing and width for overlaid RC beams at elevated temperatures." J. Struct. Eng. 639 143(12): 04017168.

640 Zhang, D., Zhao, Y., Jin, W., Ueda, T., Nakai, H. (2017b). "Shear strengthening of corroded 641 reinforced concrete columns using pet fiber based composites.” Eng. Struct. 153: 757-765.

642 Zhu, J. H., Wei, L., Guo, G., and Zhu, A. (2016). "Mechanical and Electrochemical 643 Performance of Carbon Fiber Reinforced Polymer in Oxygen Evolution Environment." 644 Polymers. 8(11): 393.

645 Zhu, J. H., Wei, L., Moahmoud, H., Redaelli, E., Feng, X., and Bertolini, L. (2017). 646 "Investigation on CFRP as dual-functional material in chloride-contaminated solutions." 647 Constr. Build. Mater. 151: 127-137. 
648 Zhu, J. H, Su, M., Huang, J., Ueda, T., and Xing, F. (2018), "The ICCP-SS technique for 649 retrofitting reinforced concrete compressive members subjected to corrosion." Constr. Build. 650 Mater. 167: 669-679. 